\title{
Anti-diabetic activities of Paecilomyces tenuipes N45 extract in alloxan-induced diabetic mice
}

\author{
LINNA DU $^{12^{*}}$, CHUNGANG LIU $^{1 *}$, MEIYU TENG $^{1}$, QINGFAN MENG $^{1}$, JIAHUI LU $^{1}$, YULIN ZHOU $^{1}$, \\ YAN LIU ${ }^{1}$, YINGKUN CHENG ${ }^{1}$, DI WANG ${ }^{1,3}$ and LESHENG TENG ${ }^{1,3}$ \\ ${ }^{1}$ School of Life Science, Jilin University, Changchun, Jilin 130012; \\ ${ }^{2}$ Engineering Research Center of Bioreactor and Pharmaceutical Development Ministry of Education, \\ Jilin Agricultural University, Changchun Jilin 130118; ${ }^{3}$ The State Engineering Laboratory of AIDS Vaccine, \\ Jilin University, Changchun, Jilin 130012, P.R. China
}

Received January 31, 2015; Accepted November 19, 2015

DOI: $10.3892 / \mathrm{mmr} .2015 .4736$

\begin{abstract}
Due to the limitations of existing anti-diabetic drugs, the treatment of diabetes mellitus remains a significant challenge. The present study aimed to investigate the hypoglycemic, hypolipidemic and antioxidant effects of Paecilomyces tenuipes N45 extracts on alloxan-induced type I diabetes mellitus in mice. Diabetic Kunming mice were orally administered with water extract (WE) at doses of $2.50,0.25$ and $0.05 \mathrm{~g} / \mathrm{kg}$ ) or alcohol extract (AE) at doses of 2.00, 0.20 and $0.04 \mathrm{~g} / \mathrm{kg}$, for 3 weeks, following which the levels of factors associated with blood glucose, lipids and free radicals were determined. The anti-diabetic activities of AE and WE were further confirmed via an oral glucose tolerance test. Similar to the effects of metformin, Paecilomyces tenuipes N45 extracts led to a significant reduction in blood glucose levels, increase in serum insulin concentration and normalization in the densities of low-density lipoprotein cholesterol and high density lipoprotein cholesterol. The Paecilomyces tenuipes N45 extracts exerted antioxidative effects, indicated by regulation in the levels of superoxide dismutase, malondialdehyde and glutathione peroxidase. Taken together, the results of the present study demonstrated that Paecilomyces tenuipes N45 extract, a safe pharmaceutical agent, exerted anti-diabetic and anti-nephropathic activities and, thus, offers potential as a novel therapeutic agent in the treatment of diabetes.
\end{abstract}

Correspondence to: Dr Di Wang, School of Life Science, Jilin University, 2699 Qianjin Street, Changchun, Jilin 130012, P.R. China E-mail: jluwangdi@gmail.com

${ }^{*}$ Contributed equally

Key words: Paecilomyces tenuipes, hypoglycemic, hypolipidemic, antioxidant

\section{Introduction}

In addition to cancer, cardiovascular disease and cerebrovascular disease, diabetes mellitus is the third leading contributor to mortality rates, and produces significant pressure on society and public health (1). As previously reported, diabetes-associated mortality rates represent almost $2.2 \%$ of the total morality rates worldwide, and its prevalence in China has increased rapidly (2-4). Complex metabolic disorders in three major nutrients, including lipids, carbohydrates and proteins, are observed in patients with diabetes (5). Insulin secretion deficiency in diabetes further results in an increase of blood glucose levels and organ damage (6). Additionally, various complications, including nephropathy, neuropathy, retinopathy and hyperlipemia, are observed in the majority of patients with diabetes (7).

As a widespread problem, traditional therapy for diabetes has focused on blood glucose regulation, which does not control the associated complications (8). At present, there remains no suitable therapeutic regimen that can cure diabetes. Insulin injection and commonly prescribed drugs, including metformin and pioglitzone, have undesirable averse effects, including insulin resistance, hypoglycemia and gastrointestinal disturbances (9). Therefore, the identification of alternative treatment strategies for the treatment of diabetes is in high demand.

Due to their reduced adverse effects and favorable economic characteristics, herbal medicine is considered a valuable reservoir of novel drugs (10). It has been revealed that natural products exhibit anti-diabetic activities and have auxiliary therapeutic effects on complications (11). Our previous study successfully demonstrated that Cordyceps militaris exhibits anti-diabetic and anti-nephropathic activities (12). Paecilomyces tenuipes, a well-known Chinese medicinal entomopathogenic fungi, has been traditionally used in folk medicine in Japan, Korea and China for years (13). Paecilomyces tenuipes, containing polysaccharides, adenosine, cordycepin, sterol and cyclopeptide, is increasingly notable for its antidepressant, antitumor and immunomodulatory effects $(14,15)$. However, the regulatory effects of a polysaccharide-enriched fraction of Paecilomyces tenuipes on diabetic mice has not been reported previously. 
In our previous study, through chemical mutagenesis, an improved mutant Paecilomyces tenuipes, termed N45, was developed, which is preserved at the China Center for Type Culture Collection (no. M2011145).

Based on our previous study, the present study hypothesized that Paecilomyces tenuipes N45 may possess anti-diabetic and hypolipidemic activities (12). The present study was designed to confirm this hypothesis in an alloxan-induced diabetic animal model. Following treatment with polysaccharide-enriched fractions of Paecilomyces tenuipes N45, indices associated with oxidation resistance, and hypoglycemic and hypolipidemic activities were detected. These data aimed to provide experimental evidence to support the clinical use of Paecilomyces tenuipes as an effective agent for the treatment of diabetes.

\section{Materials and methods}

Submerged fermentation of Paecilomyces tenuipes N45. The Paecilomyces tenuipes N45 mutant was established from Paecilomyces tenuipes Pt196 (RCEF 4339; Anhui Agricultural University, Anhui, China) via nitrosoguanidine treatment. The wild strain (RCEF4339) was cultured at $30^{\circ} \mathrm{C}$ in a potato dextrose agar (PDA) slant medium for 5 days and washed with $10 \mathrm{ml}$ of sterilized normal saline. The cell concentration was adjusted to $10^{8} / \mathrm{ml}$. The fungal suspension was treated with nitrosoguanidine ( $1 \mathrm{mg} / \mathrm{ml}$; Sinopharm Chemical Reagent Co., Ltd., Shanghai, China) for $15 \mathrm{~min}$ at room temperature. Then, the fungal suspension was cultured in PDA medium, in a rotary shaker incubator (10 1; Biostat B; Germany) at $150 \mathrm{rpm}$ for 5 days. The culture medium comprised glucose $(40 \mathrm{~g} / \mathrm{l}$; Sinopharm Chemical Reagent Co., Ltd.), peptone (10 g/l; Aoboxing Biotechnology Co., Ltd., Beijing, China) and yeast extract powder (10 g/l; Aoboxing Biotechnology Co., Ltd.). The culture temperature was $26^{\circ} \mathrm{C}$. The mycelium pellets were harvested and lyophilized for further use.

Paecilomyces tenuipes N45 extract preparation. Similar to our previous study (12), water extract from Paecilomyces tenuipes N45 (WE) was prepared, as follows: $100 \mathrm{~g}$ mycelial powder was extracted twice in 5 liters of distilled water at $80^{\circ} \mathrm{C}$ for $3 \mathrm{~h}$. Following centrifugation at 3,550 x g for $10 \mathrm{~min}$ at $4^{\circ} \mathrm{C}$, the supernatant was evaporated under reduced pressure of $0.09 \mathrm{mPa}$ and $80^{\circ} \mathrm{C}$ using a rotary evaporator $\mathrm{R} 1002 \mathrm{~B}$ obtained from Shanghai SENCO Technology Co., Ltd. (Shanghai, China) and was dissolved in physiological saline prior to use. The concentration of the WE was $0.44 \mathrm{~g} / \mathrm{ml}$ and the concentration for the alcohol extract (AE) was $0.35 \mathrm{~g} / \mathrm{ml}$. The AE was prepared using an alcohol distillation-extractor, the heating mantle used was obtained from Zhongxingweiye Instrument Co., Ltd, Beijing, China. Following removal of the existing proteins, the extracts were lyophilized by being dried using a Genesis Pilot Lyophilizer SQ 25ES (SP Industries, Inc., Warminster, PA, USA) and stored at $-20^{\circ} \mathrm{C}$.

Chemical compositions analyzed. As reported previously (16), the present study examined the levels of amino acids, polypeptides, proteins, sugars, phenolics, tannin, alkaloids, sterols, terpenes, organic acid, essential oil, anthraquinone, flavonoids, coumarin and lactone, were analyzed in the WE and AE from Paecilomyces tenuipes N45.
In vivo experiments using an animal model of diabetes. The current study was approved by the ethics committee of the Jilin University (Changchun, China). The experimental protocol was approved by the Lab Animal Centre of Jilin University. A total of 90 Kunming male mice (weight, 18-22 g; age, 6 weeks; Norman Bethune University of Medical Science Jilin University (Jilin, China) were maintained under a constant 12:12 h light-dark cycle (8:00 am-8:00 pm) at an environmental temperature of $22 \pm 1^{\circ} \mathrm{C}$ and a humidity of $60 \pm 2 \%$. The mice were fed standard chow and had access to water ad libitum prior to and following the experimental period, unless stated otherwise. All mice were fed adaptively for 1 week prior to experiments.

As shown in Fig. 1, the overnight fasted mice fed with $2 \mathrm{~g} / \mathrm{kg}$ sucrose solution for $72 \mathrm{~h}$ were used for diabetic mouse model establishment. Diabetes was induced by intraperitoneal injection with a freshly prepared solution of alloxan (Sigma-Aldrich, St Louis, MO, USA) in physiological saline at a dose of $150 \mathrm{mg} / \mathrm{kg}$ bodyweight. After $4 \mathrm{~h}$, the mice were orally administered with $25 \%$ glucose solution $(0.3-0.4 \mathrm{ml})$ to prevent fetal hypoglycemia. The same procedure was repeated on the second day. After $72 \mathrm{~h}$, mice with persistent fasting blood glucose levels $>11.1 \mathrm{mmol} / 1$ were identified as a severe diabetic group (17). Another 10 mice were fed with normal water and injected with physiological saline, and served as a control group (CTRL).

The alloxan-induced diabetic mice were separated randomly into eight groups, as follows, and received drug administration for 3 weeks (once a day):

Diabetic model group (model group; $n=10$ ): administrated with physiological saline orally; metformin group (DH group; $\mathrm{n}=10$ ): administrated with $125 \mathrm{mg} / \mathrm{kg}$ metformin (Sino-American Shanghai Squibb Pharmaceuticals Ltd, Shanghai, China) orally,

AE group: administrated orally with $2.5 \mathrm{~g} / \mathrm{kg}(\mathrm{n}=10$; equal to $5 \mathrm{~g} / \mathrm{kg}$ of dried mycelial powder), $250 \mathrm{mg} / \mathrm{kg}$ ( $\mathrm{n}=10$; equal to $0.5 \mathrm{~g} / \mathrm{kg}$ of dried mycelial powder) and $50 \mathrm{mg} / \mathrm{kg}(\mathrm{n}=10$; equal to $0.1 \mathrm{~g} / \mathrm{kg}$ of dried mycelial powder) of alcohol extract orally;

WE group: administrated with $2 \mathrm{~g} / \mathrm{kg}(\mathrm{n}=10$; equal to $5 \mathrm{~g} / \mathrm{kg}$ of dried mycelial powder), $200 \mathrm{mg} / \mathrm{kg}$ ( $\mathrm{n}=10$; equal to $0.5 \mathrm{~g} / \mathrm{kg}$ of dried mycelial powder) and $40 \mathrm{mg} / \mathrm{kg}$ ( $\mathrm{n}=10$; equal to $0.1 \mathrm{~g} / \mathrm{kg}$ of dried mycelial powder) of WE.

Bodyweight was recorded during the course of the experiment. Fasting blood glucose levels were recorded on the 21 st day following $18 \mathrm{~h}$ of food deprivation. Blood samples $(0.2 \mathrm{ml})$ were collected from the caudal vein of the mice $60 \mathrm{~min}$ after the final treatment, and the levels of superoxide dismutase (SOD), glutathione peroxidase (GSH-Px), malondialdehyde (MDA), low-density lipoprotein cholesterol (LDL-C) and high-density lipoprotein cholesterol (HDL-C) were analyzed using commercial assay kits (Nanjing Jiancheng Bioengineering Institute, Nanjing, China). Serum insulin was measured using a mouse insulin enzyme-linked immunosorbent assay kit (R\&D Systems, Inc., Minneapolis, MN, USA). Following an oral glucose tolerance test, the animals were sacrificed via administration with $200 \mathrm{mg} / \mathrm{kg}$ pentobarbital (Sinopharm Chemical Reagent Co., Ltd); following which organs (heart, liver, lungs, spleen and kidneys) were excised out, washed with ice cold saline and weighed immediately. The relative organ weights were 
Table I. Summary of the chemical constituents in crude extracts of Paecilomyces tenuipes N45.

\begin{tabular}{llc}
\hline Test & \multicolumn{1}{c}{ Reaction/test } & AE \\
\hline Amino acid/polypeptides/protein & Biuret reaction/ninhydrin reaction & - \\
Soluble reducing sugar & Fehling reagents reaction & - \\
Sugars & Open-loop reaction & + \\
Phenolics/tannin & Ferric chloride test & + \\
Alkaloids & Mercuric potassium iodide/silicotungstic acid test & - \\
Sterols & Acetic anhydride-concentrated sulfuric acid & - \\
Terpenes & Foam test & - \\
Organic acid & Bromophenol blue test & - \\
Essential oil/oil & Phospho-molybdic acid-ethanol test & - \\
Anthraquinone & Magnesium acetate test & - \\
Flavonoids & HCL-Mg powder test/HCL-Zn powder test & - \\
Coumarin/lactone & Open-loop reaction & - \\
\end{tabular}

AE, alcohol extract; WE, water extract; +, presence of compound; -, absence of compound.

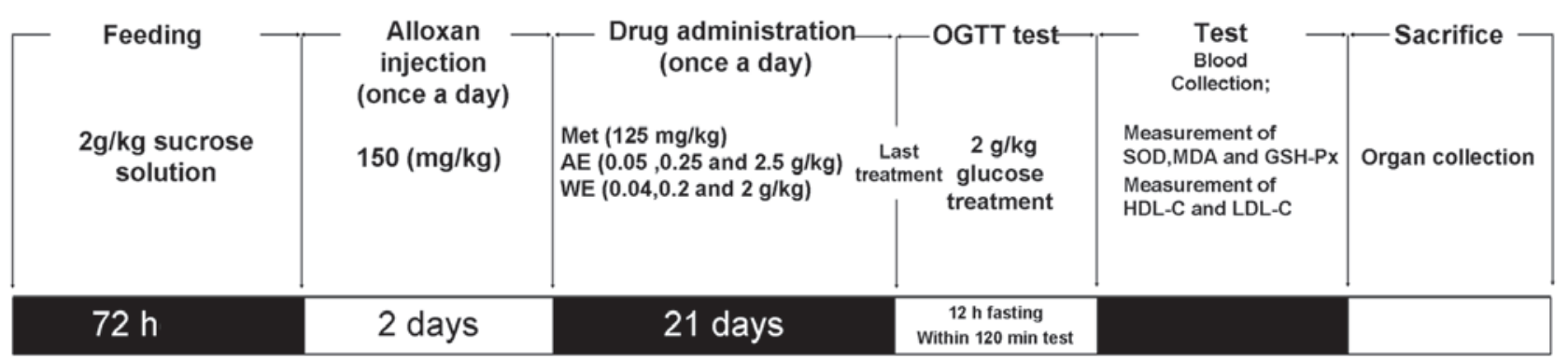

Figure 1. Experimental protocol for establishment of the alloxan-induced diabetic mouse model and drug administration. Met, metformin; AE, alcohol extract; WE, water extract; OGTT, oral glucose tolerance test; SOD, superoxide dismutase; MDA, malondialdehyde; GSH-Px, glutathione peroxidase; HDL-C, high density lipoprotein cholesterol; LDL-C, low density lipoprotein cholesterol.

calculated by dividing the weight of each organ by the weight of the mouse. The levels of SOD, GSH-Px and MDA in the liver were determined using associated commercial kits (Nanjing Biotechnology Co. Ltd., Nanjing, China).

Oral glucose tolerance test. In order to investigate glucose homeostasis in the experimental diabetic mice, an oral glucose tolerance test was performed at the end of the experiment using a previously described method with a modification (18). Following overnight, but with provision of water ad libitum for $>12 \mathrm{~h}$, the mice in all groups were administrated with the relevant extracts. After $30 \mathrm{~min}$, $2.0 \mathrm{~g} / \mathrm{kg}$ glucose was administered orally to all mice. Blood samples were collected $0,0.5,1$ and $2 \mathrm{~h}$ following the glucose load, and plasma glucose concentrations were measured using a Glucose Assay kit (Nanjing Jiancheng Bioengineering Institute). Calculation of the area under the blood glucose curve (AUC) was made according to the following equation (19): $\mathrm{AUC}=$ (basal glycemia + glycemia at $0.5 \mathrm{~h}) \times 0.25+$ (glycaemia at $0.5 \mathrm{~h}+$ glycaemia at $1 \mathrm{~h}) \times 0.25+($ glycemia at $1 \mathrm{~h}+$ glycemia at $2 \mathrm{~h}) \times 0.5$.

Statistical analysis. All data are was expressed as the mean \pm standard deviation. Statistical significance was determined using one-way analysis of variance, followed by post-hoc multiple comparisons (Dunn's test) using SPSS 16.0 software (SPSS, Inc., Chicago, IL, USA). P $\leq 0.05$ was considered to indicate a statistically significant difference.

\section{Results}

Identification of active ingredients. The screening assessment of the active ingredients revealed that soluble reducing sugar, sugars and organic acid were found in the WE and AE of Paecilomyces tenuipes N45 (Table I).

Effect of Paecilomyces tenuipes N45 extracts on bodyweight and organs. A decrease in bodyweight was found in the alloxan-induced diabetic mice during the experimental period. The suppressive effect of alloxan on bodyweight was reversed following treatment with metformin hydrochloride, and with all doses of Paecilomyces tenuipes N45 extract, with the exception of $0.05 \mathrm{~g} / \mathrm{kg} \mathrm{AE}$ and $2 \mathrm{~g} / \mathrm{kg} \mathrm{WE}$ (Fig. 2A; $\mathrm{P}<0.01$ ).

In all drug treatment groups, no significant differences were identified when relative organ weights of mice in the control group were compared with mice in the exposure groups (Table II). Compared with the control mice, the lung index was significantly increased in the alloxan-induced diabetic mice 
Table II. Effect of extracts on organ indices in alloxan-induced diabetic mice.

\begin{tabular}{lcccccc}
\hline Group & Dose $(\mathrm{g} / \mathrm{kg})$ & Heart index $(\mathrm{g} / \mathrm{g})$ & Liver index $(\mathrm{g} / \mathrm{g})$ & Spleen index $(\mathrm{g} / \mathrm{g})$ & Lung index $(\mathrm{g} / \mathrm{g})$ & Kidney index $(\mathrm{g} / \mathrm{g})$ \\
\hline CTRL & - & $5.70 \pm 0.74$ & $52.68 \pm 5.34$ & $7.27 \pm 1.66$ & $7.21 \pm 0.58$ & $7.06 \pm 0.60$ \\
Model & - & $6.12 \pm 0.79$ & $53.62 \pm 7.74$ & $7.51 \pm 2.10$ & $9.06 \pm 2.36^{\mathrm{a}}$ & $7.37 \pm 1.24$ \\
DH & 0.125 & $7.20 \pm 2.80$ & $49.65 \pm 7.61$ & $8.52 \pm 1.03$ & $7.14 \pm 1.38^{\mathrm{b}}$ & $7.69 \pm 0.71$ \\
& 0.05 & $5.89 \pm 0.44$ & $52.43 \pm 8.85$ & $6.67 \pm 2.26$ & $8.40 \pm 1.44$ & $8.07 \pm 1.36$ \\
AE & 0.25 & $5.69 \pm 1.51$ & $50.27 \pm 11.13$ & $6.67 \pm 2.46$ & $7.36 \pm 3.42^{\mathrm{b}}$ & $7.41 \pm 0.95$ \\
& 2.50 & $5.37 \pm 0.66$ & $51.69 \pm 4.32$ & $7.18 \pm 2.13$ & $7.42 \pm 1.08^{\mathrm{b}}$ & $7.57 \pm 0.61$ \\
& 0.04 & $6.40 \pm 1.07$ & $53.42 \pm 14.05$ & $8.23 \pm 1.05$ & $7.84 \pm 2.32$ & $7.90 \pm 2.09$ \\
WE & 0.20 & $6.20 \pm 1.01$ & $48.84 \pm 3.84$ & $7.09 \pm 1.27$ & $7.56 \pm 1.14^{\mathrm{b}}$ & $7.24 \pm 0.98$ \\
& 2.00 & $6.23 \pm 1.06$ & $49.98 \pm 11.23$ & $8.30 \pm 1.92$ & 7.61 .66 &
\end{tabular}

Data are expressed as organ tissue weight $(\mathrm{g}) /$ body weight $(\mathrm{g})$, and are presented as the mean \pm standard deviation $(\mathrm{n}=10) .{ }^{\mathrm{a}} \mathrm{P}<0.05$, compared with the CTRL group; ${ }^{\mathrm{b}} \mathrm{P}<0.05$, compared with the model group. CTRL, untreated control; Model, diabetes model; DH, metformin; AE, alcohol extract; WE, water extract.
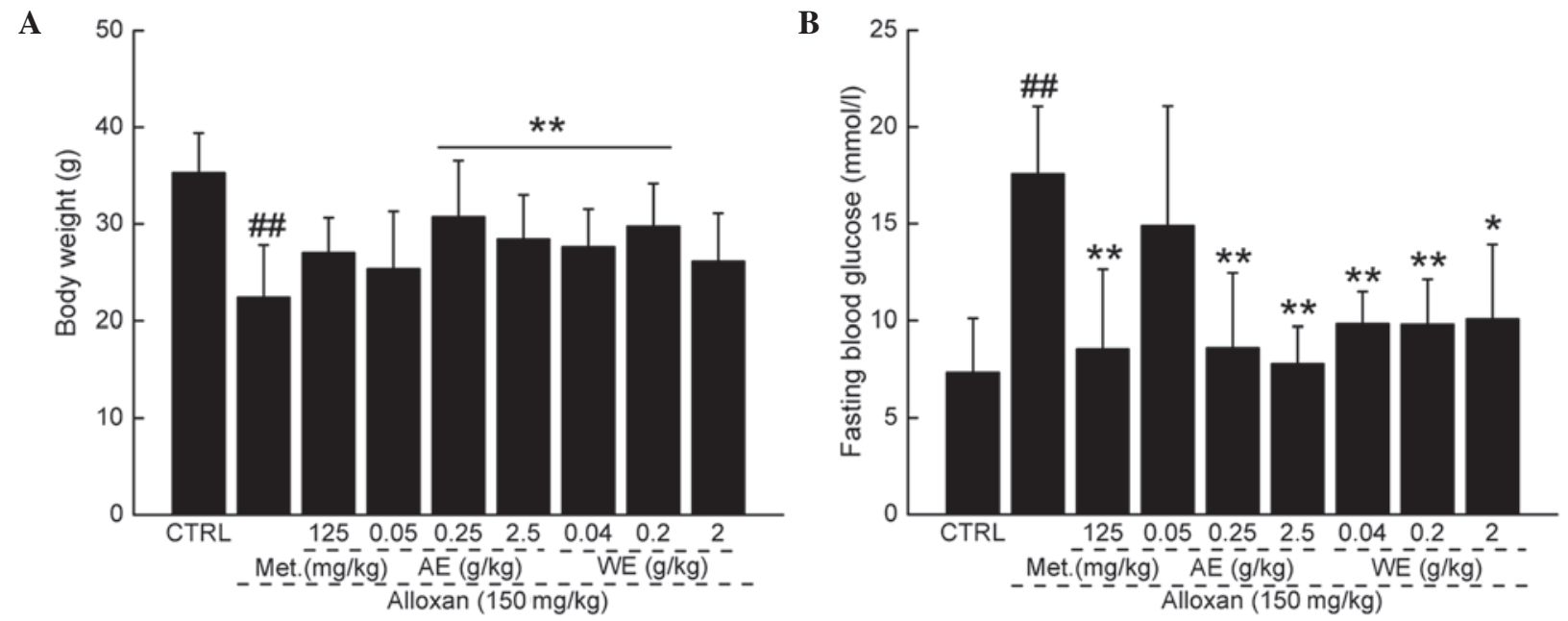

Figure 2. A mouse model of diabetes was established by $72 \mathrm{~h}$ sucrose administration and $48 \mathrm{~h}$ alloxan injection. Untreated mice served as control group. The diabetic mice were treated with or without $125 \mathrm{mg} / \mathrm{kg}$ metformin and Paecilomyces tenuipes N45 extracts at various doses for another 3 weeks. The changes in (A) bodyweights and (B) fasting plasma glucose were detected. Data are expressed as the mean \pm standard deviation ( $\mathrm{n}=10$ ) and were analyzed using one-way analysis of variance, followed by Dunn's test. ${ }^{\# \#} \mathrm{P}<0.01$, vs. CTRL; ${ }^{*} \mathrm{P}<0.05$ and ${ }^{* *} \mathrm{P}<0.01$, vs. alloxin-induced model group. CTRL, untreated control; AE, alcohol extract; WE, water extract; Met, metformin.

$(\mathrm{P}<0.05)$. Treatment for 21 days with metformin hydrochloride, AE and WE suppressed lung hyperplasia (Table II).

Paecilomyces tenuipes N45 extracts exert hypoglycemic effects. Fasting blood glucose levels were measured to evaluate the hypoglycemic effects of Paecilomyces tenuipes N45 extracts. The fasting blood glucose concentration in the alloxan-induced diabetic mice was $11.1 \mathrm{mmol} / \mathrm{l}$ higher than that of the normal control animal group; whereas treatment with $125 \mathrm{mg} / \mathrm{kg}$ metformin hydrochloride resulted in a $51.24 \%$ reduction in fasting blood glucose concentration $(\mathrm{P}<0.01$; Fig. $2 \mathrm{~B})$. The administration of 0.25 and $2.5 \mathrm{~g} / \mathrm{kg}$ AE reduced fasting blood glucose levels by almost 44.29 and $50.53 \%$, respectively $(\mathrm{P}<0.01$; Fig. 2B), compared with the model group. Similarly, administration of $0.04,0.2$ and $2 \mathrm{~g} / \mathrm{kg}$ WE suppressed fasting blood glucose levels by $40.70,56.72$ and $37.31 \%$, respectively, compared with the model group $(\mathrm{P}<0.01$; Fig. $2 \mathrm{~B})$.
The oral glucose tolerance test served as a second diagnostic indices to further confirm the hypoglycemic effects of Paecilomyces tenuipes N45 extracts (20). Significantly higher fasting blood glucose levels were observed in the alloxan-induced diabetic mice between 0.5 and $2 \mathrm{~h}$, compared with the normal mice $(\mathrm{P}<0.05$; Fig. $3 \mathrm{~A})$. Similar to the results following exposure to metformin hydrochloride, AE and WE significantly prevented the rapid increase in blood glucose levels, particularly at $60 \mathrm{~min}(\mathrm{P}<0.05$; Fig. 3A). High AUC values in the model group revealed a state of impaired glucose tolerance in the diabetic mice $(\mathrm{P}<0.01$; Fig. $3 \mathrm{~B})$. Treatment with metformin hydrochloride, $\mathrm{AE}$ and WE significantly reduced the AUC during the oral glucose tolerance test $(\mathrm{P}<0.05$; Fig. 3B).

Paecilomyces tenuipes N45 extracts increase plasma levels of insulin and hepatic glycogen. Compared with the 

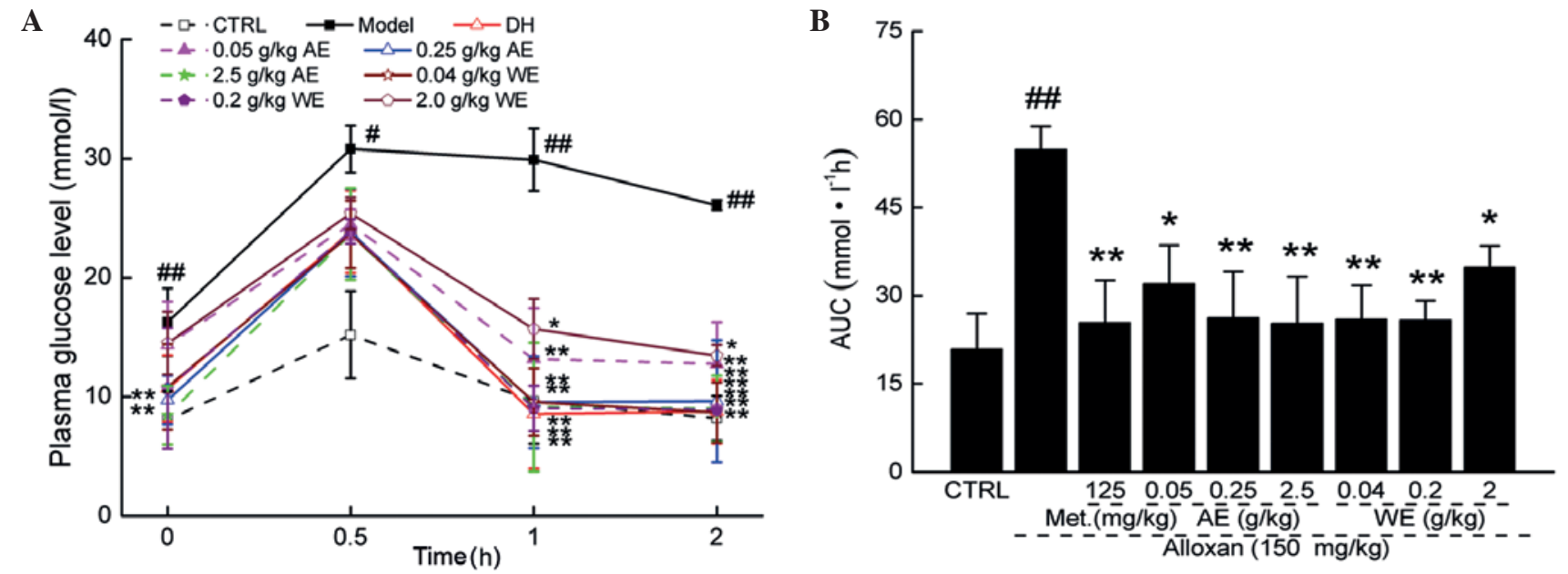

Figure 3. (A) Blood glucose levels and the (B) AUC of the OGTT in normal and diabetic mice in the OGTT. Data are expressed as the mean \pm standard deviation ( $\mathrm{n}=10)$. ${ }^{\text {}} \mathrm{P}<0.05$ and ${ }^{\# \prime} \mathrm{P}<0.01$, vs. CTRL; $\mathrm{P}<0.05$ and ${ }^{* *} \mathrm{P}<0.01$, vs. alloxin-induced model group. AUC, area under curve; $\mathrm{CTRL}$, untreated control; AE, alcohol extract; WE, water extract; Met, metformin; DH, metformin group.

A

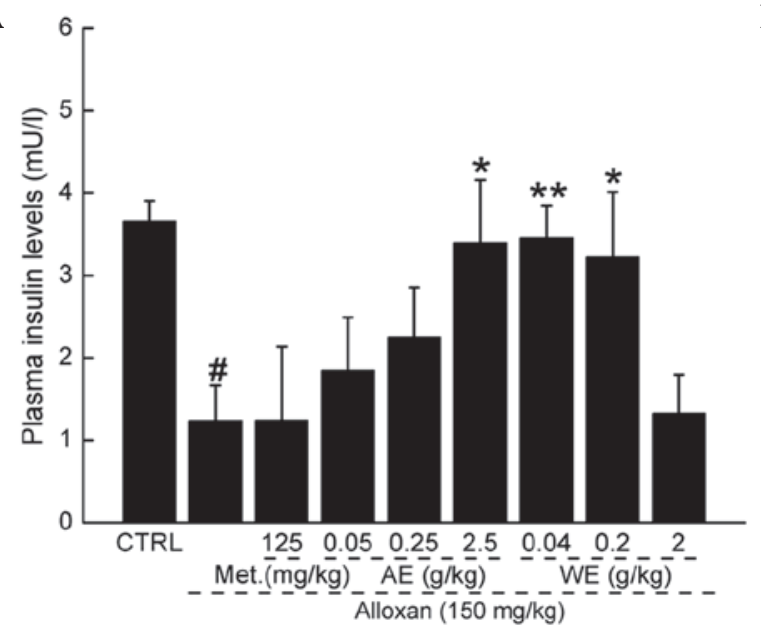

B

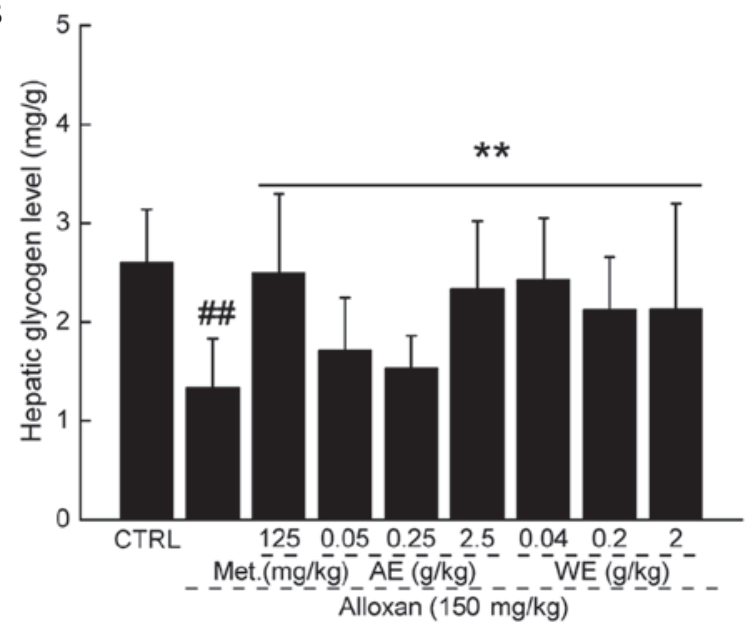

Figure 4. Administration of AE and WE for 3 weeks significantly enhanced the levels of (A) serum insulin and (B) hepatic glycogen in diabetic mice. Data are expressed as the mean \pm standard deviation $(\mathrm{n}=10)$. ${ }^{\#} \mathrm{P}<0.05$ and ${ }^{\# \#} \mathrm{P}<0.01$, vs. CTRL; ${ }^{*} \mathrm{P}<0.05$ and ${ }^{* *} \mathrm{P}<0.01$, vs. alloxin-induced model group. CTRL, untreated control; AE, alcohol extract; WE, water extract; Met, metformin.

A

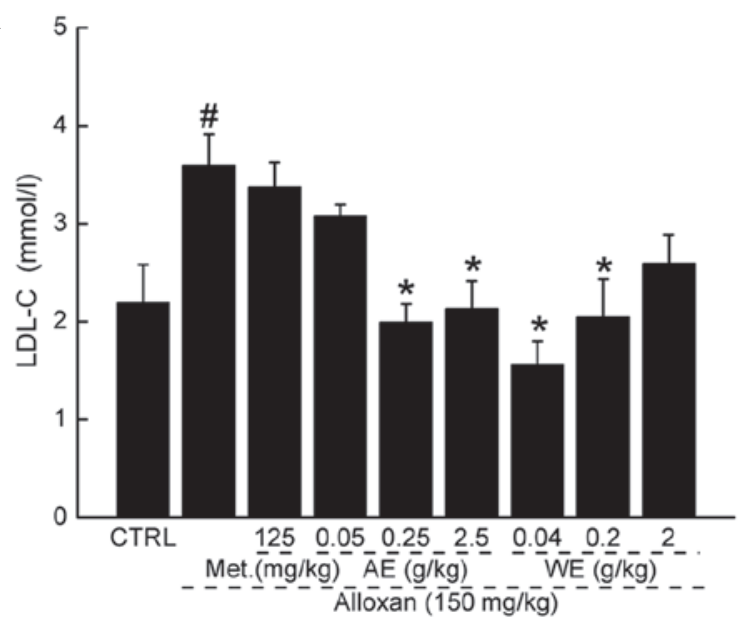

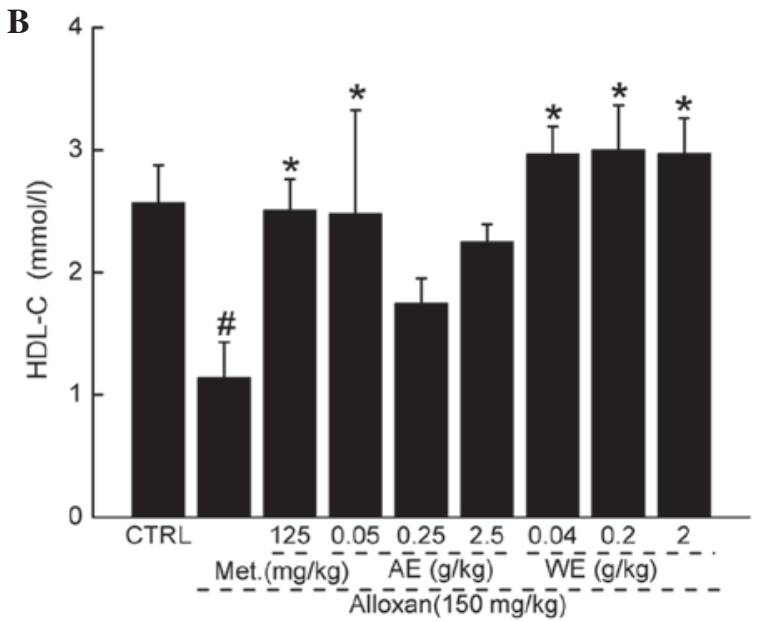

Figure 5. Hypolipidemic effects of Paecilomyces tenuipes N45 extracts on alloxan-induced diabetic mice. Administration of AE and WE for 3 weeks resulted in a reduction in (A) LDL-C (A) and an increase in (B) HDL-C in the serum, compared with the diabetic model mice. Data are expressed as the mean \pm standard deviation $(\mathrm{n}=10)$ and were analyzed using one-way analysis of variance, followed by Dunn's test. ${ }^{~} \mathrm{P}<0.05$, vs. CTRL; " $\mathrm{P}<0.05$, vs. alloxin-induced model group. CTRL, untreated control; AE, alcohol extract; WE, water extract; Met, metformin; HDL-C, high density lipoprotein cholesterol; LDL-C, low density lipoprotein cholesterol. 
A

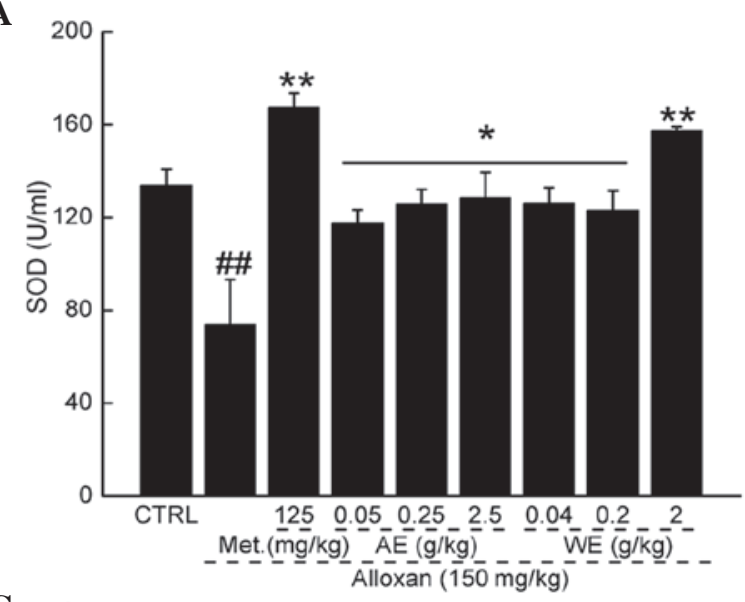

C

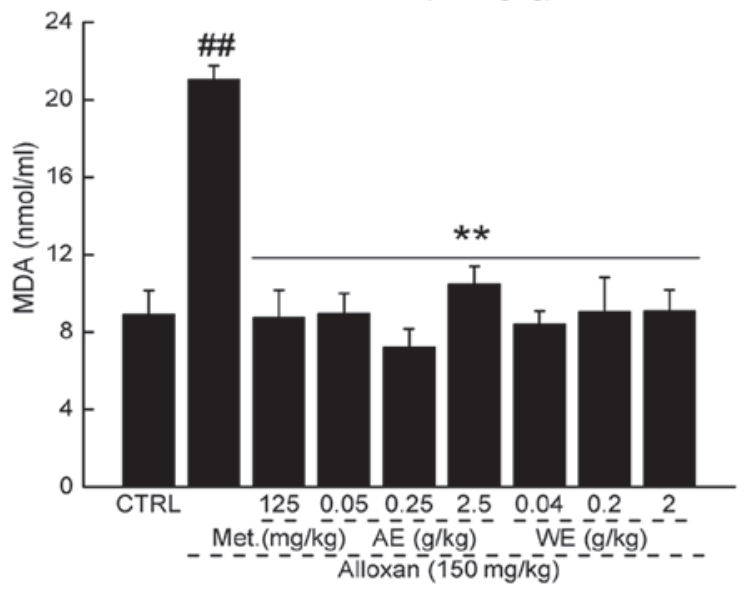

$\mathbf{E}$

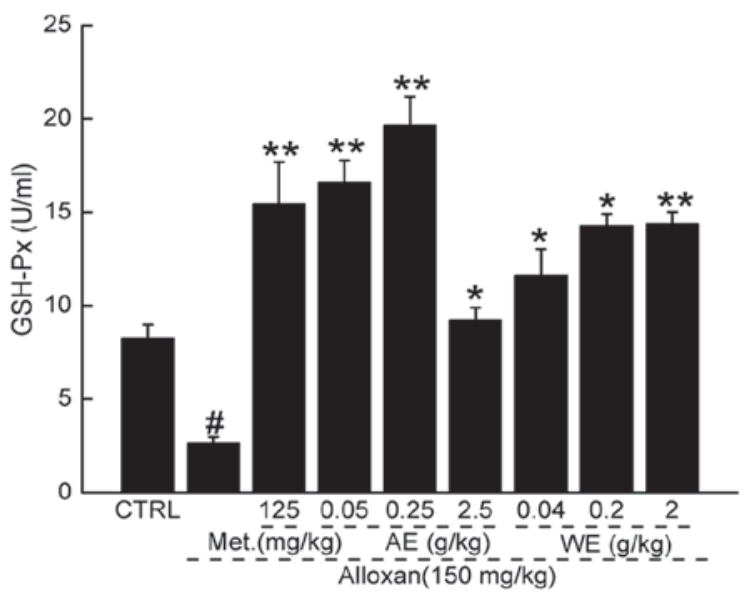

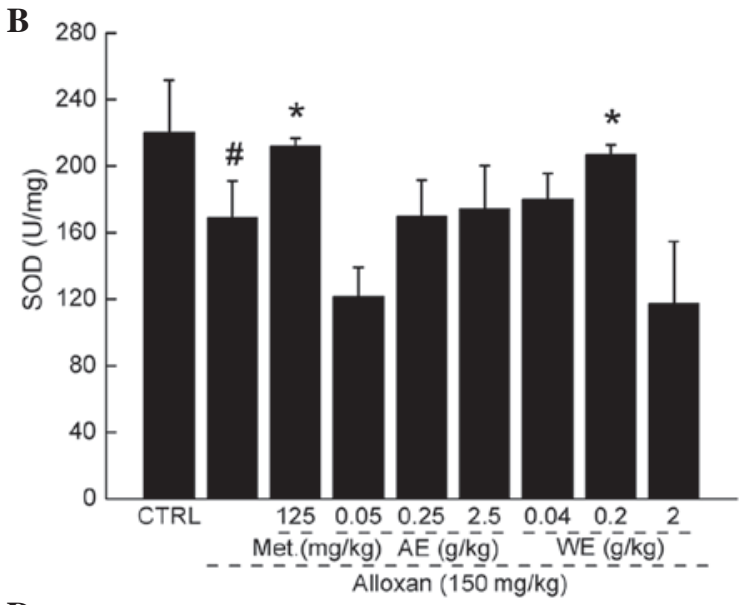

D
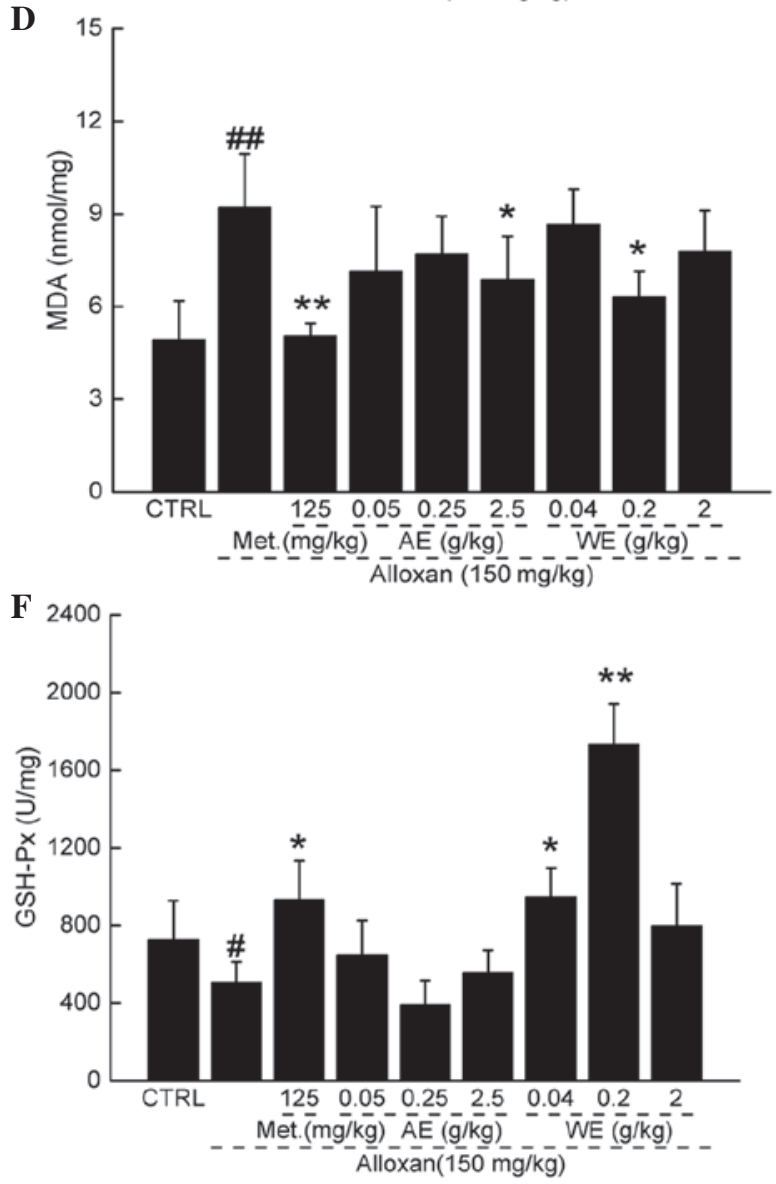

Figure 6. Antioxidative effects of Paecilomyces tenuipes N45 extracts on alloxan-induced diabetic mice. The levels of (A and B) SOD, (C and D) MDA and (E and F) GSH-Px in the plasma and liver, respectively, were detected. Data are expressed as the mean \pm standard deviation ( $\mathrm{n}=10)$ and were analyzed using one-way analysis of variance, followed by Dunn's test. " $\mathrm{P}<0.05$ and ${ }^{\# \#} \mathrm{P}<0.01$, vs. CTRL; ${ }^{*} \mathrm{P}<0.05$ and ${ }^{\text {***}} \mathrm{P}<0.01$, vs. alloxin-induced model group.

untreated group, a significant decrease in plasma insulin levels was observed following alloxan treatment. AE and WE treatment resulted in the elevation of plasma insulin levels (Fig. 4A; $\mathrm{P}<0.01$ ). The synthesis and degradation of glycogen in the liver are important mechanisms in the control of blood glucose homeostasis (21). Hepatic glycogen levels were measured to determine whether elevation of hepatic glycogen is involved in the hypoglycemic effects of the extracts. The levels of hepatic glycogen measured at the termination of the various treatments are shown in Fig. 4B. Significant decreases in hepatic glycogen were observed in the diabetic mice. As expected, repeated oral treatment with metformin hydrochloride, and all extract doses caused a marked increase in the levels of hepatic glycogen, compared with the diabetic model group (Fig. 4B; $\mathrm{P}<0.01$ ).

Paecilomyces tenuipes N45 extracts exert hypolipidemic effects. In diabetic mice, significantly high levels of low-density lipoprotein cholesterol (LDL-C) were observed. AE and WE administration reduced the concentrations of LDL-C to normal levels (Fig. 5A; $\mathrm{P}<0.05$ ). By contrast, compared with the untreated mice, alloxan injection reduced the concentrations of high density lipoprotein cholesterol (HDL-C). AE administration at $0.05 \mathrm{~g} / \mathrm{kg}$, and $\mathrm{WE}$ at all doses, increased 
the low level of HDL after 4-week treatment (Fig. 5B; P<0.05). The therapeutic effect on HDL was noted in metformin hydrochloride-treated mice (Fig. 5B; $\mathrm{P}<0.05$ ).

Paecilomyces tenuipes $N 45$ extracts exert antioxidant effects. Hyperglycemia-induced oxidative stress leads to excessive production of reactive oxygen species (ROS), which may be responsible for the pathogenesis of diabetes-associated complications (22). SOD and GSH-Px, important antioxidant enzymes in mammalian cells, have critical roles against oxidative stress-induced cell damage (23). In the present study, following alloxan injection, the levels of SOD and GSH-Px in the plasma and liver were reduced significantly; whereas the concentration of MDA was significantly enhanced (Fig. 6A-F; P<0.05). Similar to metformin hydrochloride, AE and WE administration normalized the levels of SOD, GSH-Px and MDA to healthy levels in the plasma and liver (Fig. 6; P<0.05).

\section{Discussion}

Due to various pathologic changes, diabetes has become the third leading contributor to mortality rates worldwide (24). As reported previously, natural products, which possess antidiabetic activity offer a valuable reservoir of potential diabetes medications (25). Fungi have received increasing attention, as they have comprehensive hypoglycemic effects $(25,26)$. Paecilomyces tenuipes has been considered to be a valuable source of medicinal remedies and health promotion. $(27,28)$. The immune-stimulating and antifatigue activities of Paecilomyces tenuipes have been investigated in animal models $(14,29)$. In the present study, based on fermentation culture, the hypoglycemic effects associated with fasting blood glucose levels of Paecilomyces tenuipes N45 extracts were successfully investigated in an alloxan-induced diabetic mouse model. In addition, the hypolipidemic and antioxidative activities of Paecilomyces tenuipes N45 extracts were confirmed. Through bodyweight and monitoring of visceral indices, Paecilomyces tenuipes N45 was confirmed as a safe pharmacological agent.

Various methods of chemical analysis were applied to detect the composition of Paecilomyces tenuipes N45 crude extracts. Soluble reducing sugar, sugars and organic acids were found in WEs and AEs. Although natural products are generally accepted as safe and efficacious for clinical use, pharmacological and toxicological evaluations are necessary (30). In our previous investigations, through histopathological detection, and hematological and biochemical analyses, Paecilomyces tenuipes N45 was found to have no adverse effects in terms of acute oral toxicity or 90-day subchronic inhalation toxicity (31). In the present study, compared with the untreated mice, minimal change in organ indices were noted, which further confirmed the safety of Paecilomyces tenuipes N45.

The pancreas is responsible for the regulation of glucose concentrations in the plasma. Alloxan, an uncommon substance used for diabetes mellitus establishment, possesses a destructive activity on the $\beta$-cells of the pancreas $(32,33)$. Through damage of $\beta$-cells, alloxan causes a reduction in insulin release, thereby inducing hyperglycemia (34). As reported, the antihyperglycemic activity of natural products is predominantly due to their activity in restoring pancreatic function by increasing insulin output (11). Similarly, the data in the present study confirmed that the WEs and AEs of Paecilomyces tenuipes N45 suppressed the alloxan-elevated levels of serum insulin. However, whether Paecilomyces tenuipes $\mathrm{N} 45$ reverses increasing insulin secretion through the regeneration of damaged $\beta$-cells requires further investigation.

Due to the increase in free fatty acid mobilization, abnormally high serum lipid concentrations are were observed in the diabetic animals. Compared with the alloxan-induced diabetic mice, Paecilomyces tenuipes N45 extracts reduced serum LDL-C concentrations, whereas the serum levels of HDL-C were markedly enhanced 21 days following extract administration. The above effects may be beneficial in preventing various complications, including coronary heart diseases (35) and atherosclerosis (36).

The levels of liver glycogen, an important reserve of glucose, were also measured in the present study. Administration of the extracts, at all doses, enhanced the abnormally low levels of liver glycogen in the diabetic mice, indicating that it may be a target involved in Paecilomyces tenuipes N45-mediated hypoglycemic activities.

ROS accumulate in diabetic patients due to disequilibrium in the production and the scavenging effects on free radicals $(37,38)$. Abnormal high glucose concentrations causes the autooxidation and autooxidative glycosylation of proteins (20), which leads to damage of proteins, lipids and nucleic acids $(39,40)$. The use of antioxidant compounds are considered an effective method to prevent or inhibit pancreatic $\beta$-cell destruction caused by alloxan (41). The data obtained in the present study confirmed that the antioxidant activity of SOD and GSH-Px in diabetes mellitus is associated with higher concentrations of peroxide (42). Paecilomyces tenuipes N45-mediated hypoglycemic activities may be associated with its normalization effects on the levels of SOD, MDA and GSH-Px in the plasma and liver.

In conclusion, the results of the present study indicated that the extracts of Paecilomyces tenuipes N45 prevented the increased fasting plasma glucose levels induced by alloxan. The plasma glucose lowering effects of the extracts may be explained by improving blood glucose and insulin homeostasis, enhancing the levels of liver glycogen and improving antioxidant levels. This primary investigation on the antihyperglycemic, antihyperlipidemic and antioxidant efficacy of Paecilomyces tenuipes N45 extracts may assist in isolating the active principles responsible for antidiabetic effects.

\section{Acknowledgements}

This study was supported by the National Science and Technology Support Program of China (grant no. 2012BAL29B05), the National Natural Science Foundation of China (grant no. 81402955) and the Science and Technology Key Project (grant no. 20130201006ZY).

\section{References}

1. Wild S, Roglic G, Green A, Sicree R and King H: Global prevalence of diabetes: Estimates for the year 2000 and projections for 2030. Diabetes Care 27: 1047-1053, 2004. 
2. Hu D, Fu P, Xie J, Chen CS, Yu D, Whelton PK, He J and Gu D; MS for the InterASIA Collaborative Group: Increasing prevalence and low awareness, treatment and control of diabetes mellitus among Chinese adults: The InterASIA study. Diabetes Res Clin Pract 81: 250-257, 2008.

3. Wang W, Fu CW, Pan CY, Chen W, Zhan S, Luan R, Tan A, Liu Z and Xu B: How do type 2 diabetes mellitus-related chronic complications impact direct medical cost in four major cities of urban China? Value Health 12: 923-929, 2009.

4. Wang H, Qiu Q, Tan LL, Liu T, Deng XQ, Chen YM, Chen W, $\mathrm{Yu} \mathrm{XQ}, \mathrm{Hu} \mathrm{BJ}$ and Chen WQ: Prevalence and determinants of diabetes and impaired fasting glucose among urban community-dwelling adults in Guangzhou, China. Diabetes Metab 35: 378-384, 2009

5. Kerner W and Brückel J; German Diabetes Association: Definition, classification and diagnosis of diabetes mellitus. Exp Clin Endocrinol Diabetes 122: 384-386, 2014.

6. You Q, Chen F, Wang X, Luo PG and Jiang Y: Inhibitory effects of muscadine anthocyanins on $\alpha$-glucosidase and pancreatic lipase activities. J Agric Food Chem 59: 9506-9511, 2011

7. Winkler G, Hidvegi T, Vandorfi G, Balogh S and Jermendy G: Risk-stratified screening for type 2 diabetes in adult subjects: Results from Hungary. Diabetologia 54: S119-S120, 2011.

8. Kania DS, Gonzalvo JD and Weber ZA: Saxagliptin: A clinical review in the treatment of type 2 diabetes mellitus. Clin Ther 33: 1005-1022, 2011

9. Scheen AJ: Antidiabetic agents in subjects with mild dysglycaemia: Prevention or early treatment of type 2 diabetes? Diabetes Metab 33: 3-12, 2007

10. Novak M and Vetvicka V: Beta-glucans, history and the present: Immunomodulatory aspects and mechanisms of action. J Immunotoxicol 5: 47-57, 2008.

11. Malviya N, Jain S and Malviya S: Antidiabetic potential of medicinal plants. Acta Pol Pharm 67: 113-118, 2010.

12. Dong Y, Jing T, Meng Q, Liu C, Hu S, Ma Y, Liu Y, Lu J, Cheng Y, Wang D and Teng L: Studies on the antidiabetic activities of Cordyceps militaris extract in diet-streptozotocin-induced diabetic Sprague-Dawley rats. Biomed Res Int 2014: 160980, 2014

13. Fukatsu T, Sato $\mathrm{H}$ and Kuriyama H: Isolation, inoculation to insect host and molecular phylogeny of an entomogenous fungus Paecilomyces tenuipes. J Invertebr Pathol 70: 203-208, 1997.

14. Chen X, Lu J, Zhang Y, He J, Guo X, Tian G and Jin L: Studies of macrophage immuno-modulating activity of polysaccharides isolated from Paecilomyces tenuipes. Int J Biol Macromol 43 : 252-256, 2008

15. Ahn MY, Jung YS, Jee SD, Kim CS, Lee SH, Moon CH, Cho SI, Lee BM and Ryu KS: Anti-hypertensive effect of the Dongchunghacho, Isaria sinclairii, in the spontaneously hypertensive rats. Arch Pharm Res 30: 493-501, 2007

16. Hong IP, Nam SH, Sung GB, Chung IM, Hur H, Lee MW, Kim MK and Guo SX: Chemical Components of Paecilomyces tenuipes (Peck) Samson. Mycobiology 35: 215-218, 2007.

17. Federiuk IF, Casey HM, Quinn MJ, Wood MD and Ward WK: Induction of type-1 diabetes mellitus in laboratory rats by use of alloxan: Route of administration, pitfalls and insulin treatment. Comp Med 54: 252-257, 2004. ;

18. ParkS,KimdaS,KimJH,KimJS andKimHJ:Glyceollin-containing fermented soybeans improve glucose homeostasis in diabetic mice. Nutrition 28: 204-211, 2012.

19. Subramanian R, Asmawi MZ and Sadikun A: In vitro alpha-glucosidase and alpha-amylase enzyme inhibitory effects of Andrographis paniculata extract and andrographolide. Acta Biochim Pol 55: 391-398, 2008.

20. Park JH, Park NS, Lee SM and Park E: Effect of Dongchunghacho rice on blood glucose level, lipid profile and antioxidant metabolism in streptozotocin-induced diabetic rats. Food Science and Biotechnology 20: 933-940, 2011.

21. Wu SY, Wang GF, Liu ZQ, Rao JJ, Lü L, Xu W, Wu SG and Zhang JJ: Effect of geniposide, a hypoglycemic glucoside, on hepatic regulating enzymes in diabetic mice induced by a high-fat diet and streptozotocin. Acta Pharmacol Sin 30 : 202-208, 2009

22. Rubattu S, Pagliaro B, Pierelli G, Santolamazza C, Castro SD, Mennuni S and Volpe M: Pathogenesis of target organ damage in hypertension: Role of mitochondrial oxidative stress. Int J Mol Sci 16: 823-839, 2014.

23. Baynes JW: Role of oxidative stress in development of complications in diabetes. Diabetes 40: 405-412, 1991.
24. Qi LW, Liu EH, Chu C, Peng YB, Cai HX and Li P: Anti-diabetic agents from natural products-an update from 2004 to 2009. Curr Top Med Chem 10: 434-457, 2010.

25. Yang BK, Jung YS and Song CH: Hypoglycemic effects of Ganoderma applanatum and Collybia confluens exo-polymers in streptozotocin-induced diabetic rats. Phytother Res 21: 1066-1069, 2007

26. Zhang G, Huang Y, Bian Y, Wong JH, Ng TB and Wang $\mathrm{H}$ : Hypoglycemic activity of the fungi Cordyceps militaris, Cordyceps sinensis, Tricholoma mongolicum and Omphalia lapidescens in streptozotocin-induced diabetic rats. Appl Microbiol Biotechnol 72: 1152-1156, 2006.

27. Nam SH, Li CR, Li ZZ, Fan MZ, Kang SW, Lee KG, Yeo JH, Hwang JS, Choi JY, Han SM and Lee KM: Long-term preservation, regeneration and cultivation of Paecilomyces tenuipes (Peck) Samson (Ascomycetes), an entomopathogenic fungus inoculated into the silkworm larva of Bombyx mori. Int J Med Mushrooms 13: 83-91, 2011.

28. Chung EJ, Choi K, Kim HW and Lee DH: Analysis of cell cycle gene expression responding to acetoxyscirpendiol isolated from Paecilomyces tenuipes. Biol Pharm Bull 26: 32-36, 2003.

29. Takata T, Tanaka T, Yahagi N, Yahagi R, Tsuchida H, Ishigaki Y, Tomosugi N, Fushiya S, Takano F and Ohta T: The liquid culture filtrates of entomogenous fungus Paecilomyces tenuipes and its glycoprotein constituent protects against anemia in mice treated with 5-fluorouracil. Biol Pharm Bull 31: 1565-1573, 2008.

30. lbarrola DA, Hellión-lbarrola MC, Montalbetti Y, Heinichen O, Alvarenga N, Figueredo A and Ferro EA: Isolation of hypotensive compounds from Solanum sisymbriifolium Lam. J Ethnopharmacol 70: 301-307, 2000

31. Du L, Liu Y, Liu C, Meng Q, Song J, Wang D, Lu J, Teng L, Zhou $\mathrm{Y}$ and Teng L: Acute and subchronic toxicity studies on safety assessment of Paecilomyces tenuipes N45 extracts. Comb. Chem. High Throughput Screen 18: 809-818, 2015.

32. Balamurugan K, Nishanthini A and Mohan VR: Antidiabetic and antihyperlipidaemic activity of ethanol extract of Melastoma malabathricum Linn. Leaf in alloxan induced diabetic rats. Asian Pac J Trop Biomed 4 (Suppl 1): S442-S448, 2014.

33. Nakahara Y, Ozaki K, Sano T, Kodama Y and Matsuura T: Assessment of alloxan-induced diabetic rats as a periodontal disease model using a selective cyclooxygenase (COX)-2 inhibitor. J Toxicol Pathol 27: 123-129, 2014.

34. Kumar V, Mahdi F, Khanna AK, Singh R, Chander R, Saxena JK, Mahdi AA and Singh RK: Antidyslipidemic and antioxidant activities of Hibiscus rosa sinensis root extract in Alloxan induced diabetic rats. Indian J Clin Biochem 28: 46-50, 2013.

35. Ripley DP, Motwani M, Plein S and Greenwood JP: Established and emerging cardiovascular magnetic resonance techniques for the assessment of stable coronary heart disease and acute coronary syndromes. Quant Imaging Med Surg 4: 330-344, 2014.

36. Chinetti-Gbaguidi G, Colin S and Staels B: Macrophage subsets in atherosclerosis. Nat Rev Cardiol 12: 10-17, 2015.

37. Yao Y, Sang W, Zhou M and Ren G: Antioxidant and alpha-glucosidase inhibitory activity of colored grains in China. J Agric Food Chem 58: 770-774, 2010.

38. Adisa RA, Choudhary MI and Olorunsogo OO: Hypoglycemic activity of Buchholzia coriacea (Capparaceae) seeds in streptozotocin-induced diabetic rats and mice. Exp Toxicol Pathol 63: $619-625,2011$

39. Sharma M, Akhtar N, Sambhav K, Shete G, Bansal AK and Sharma SS: Emerging potential of citrus flavanones as an antioxidant in diabetes and its complications. Curr Top Med Chem 15: 187-195, 2015.

40. Monea A, Mezei T, Popsor S and Monea M: Oxidative stress: A link between diabetes mellitus and periodontal disease. Int J Endocrinol 2014: 917631, 2014.

41. Sebai H, Selmi S, Rtibi K, Souli A, Gharbi N and Sakly M: Lavender (Lavandula stoechas L.) essential oils attenuate hyperglycemia and protect against oxidative stress in alloxan-induced diabetic rats. Lipids Health Dis 12: 189, 2013.

42. Suryawanshi NP, Bhutey AK, Nagdeote AN, Jadhav AA and Manoorkar GS: Study of lipid peroxide and lipid profile in diabetes mellitus. Indian J Clin Biochem 21: 126-130, 2006. 